\title{
A ESCUTA ANALÍTICA COMO INSTRUMENTO DE RESGATE E MANUTENÇÃO DO LAÇO SOCIAL
}

Maria Manuela Dias Ramos de Macedo

Universidade Federal Fluminense

Perla Klautau

Universidade Federal do Rio de Janeiro
Recebido em: 31/07/2020

$1^{\text {a }}$ revisão em: 29/09/2020

Aceito em: 08/11/2020

\section{RESUMO}

O presente trabalho é fruto do projeto "Jovens em situação de vulnerabilidade social: entre o trauma e o reconhecimento" desenvolvido com bolsa de iniciação científica concedida pela FAPERJ. Ao longo do trabalho, observamos que a emergência de pequenos testemunhos mobilizava os participantes. Embora a narrativa fosse de uma experiência dolorosa, o posterior acolhimento atuava como potencializador de vínculos sociais. Nesse sentido, propomos examinar a função clínica do testemunho para a atuação dos analistas em contextos de precarização, onde há o enfraquecimento dos laços discursivos. Para isso, partimos da premissa que a vivência em condições precárias é potencialmente traumática e excludente, ainda que haja um esforço psíquico de reduzir a importância dessas situações, banalizando o sofrimento oriundo da violência simbólica a que estão submetidos. Nossa aposta é que a escuta analítica pode operar como um instrumento de cuidado, tendo na coletividade a força para o resgate e manutenção do laço social.

Palavras-chave: desamparo; trauma psíquico; laço social. 


\title{
ANALYTICAL LISTENING AS A RESCUE AND MAINTENANCE INSTRUMENT OF THE SOCIAL BOND
}

\begin{abstract}
This paper is result of a research developed with a scientific initiation grant from FAPERJ. Throughout the work, we observed that the emergence of small testimonies mobilized the participants. Although the narrative was of a painful experience, the subsequent reception acted as a potentializer of social bonds. In this sense, we propose to examine the clinical function of testimony for the performance of analysts in precarious contexts, where there is a weakening of discourse bonds. For this, we start from the premise that living in precarious conditions is potentially traumatic and excluding, even though there is a psychological effort to reduce the importance of these situations, trivializing the suffering resulting from the symbolic violence to which they are subjected. Our belief is that analytical listening can operate as a potential care instrument, having in the collectivity the strength to rescue and maintain the social bond.
\end{abstract}

Keywords: helplessness; psychic trauma; social ties. 


\section{ESCUCHA ANALÍTICA COMO INSTRUMENTO DE RESCATE Y MANTENIMIENTO DEL LAZO SOCIAL}

\section{RESUMEN}

Este trabajo es resultado de una investigación desarrollada con una beca de iniciación científica de FAPERJ. Durante la investigación de campo, observamos que la aparición de pequeños testimonios movilizaba a los participantes. Aunque la narración fuese una experiencia dolorosa, la recepción posterior actuó como un fortalecimiento de los lazos sociales En este sentido, proponemos examinar la función clínica del testimonio para la actuación de los analistas en contextos precarios, donde hay un debilitamiento de los lazos discursivos. Para esto, partimos de la premisa de que vivir en condiciones precarias es potencialmente traumático y excluyente, a pesar de que existe un esfuerzo psicológico para reducir la importancia de estas situaciones, trivializando el sufrimiento resultante de la violencia simbólica a la que están sujetos. Nuestra apuesta es que la escucha analítica puede funcionar como un instrumento de atención potencial, con la comunidad teniendo la fuerza para rescatar y mantener el vínculo social.

Palabras clave: desamparo; trauma psiquico; lazo social. 


\section{INTRODUÇÃO}

\section{A ATUAÇÃO DO PSICANALISTA EM CONDIÇÕES PRECÁRIAS}

Diversos são os psicanalistas que estão atuando no alargamento da aplicabilidade da psicanálise, visando especialmente a sua utilização nos espaços sociais (Broide \& Broide, 2016; Rosa, 2015; Dunker, 2016). Se pensarmos a situação de vulnerabilidade social como uma equação matemática, essa pode ser considerada produto do somatório dos seguintes fatores: precariedade, condição precária e precarização. Em contextos de vulnerabilidade social, a construção de dispositivos grupais fundamentados na escuta analítica tem se mostrado um potente instrumento clínico político de cuidado e de inclusão social, o qual opera no sentido de potencializar os vínculos entre os sujeitos, tão afrouxados pela lógica individualizante e excludente da sociedade contemporânea.

Tomando a referida operação matemática como norteador, faz-se necessária a distinção dos seguintes termos: precário, precariedade, condição precária e precarização. Embora gramaticalmente compartilhem o mesmo radical, sua diferenciação conceitual é crucial para a investigação proposta.

Segundo o dicionário Aurélio (Ferreira, 1986), precário é um adjetivo que deriva do latim precariu, podendo significar: difícil, minguado, estreito; escasso, raro, pouco, insuficiente; incerto, vário, contingente, inconsistente; pouco durável, insustentável ou ainda delicado, débil. Enquanto precariedade é um substantivo, o qual faz referência à qualidade ou ao estado de precário.

Butler (2018) desloca tais termos para o campo da vida e propõe uma gradação de sentidos referente aos vocábulos precariedade, condição precária e precarização. Sobre a precariedade, a autora a entende como uma condição existencial para todos os humanos, considerando o nascimento como um momento no qual o bebê não cumpre as mínimas exigências para sua sobrevivência. Ou seja, há uma precariedade natural, traço da condição humana, que faz com que o recém-nascido dependa de uma rede de semelhantes que o ampare e o suporte.

Sabemos, então, que a precariedade é uma condição inerente da humanidade, já que todos nós dependemos de redes de sociabilidade. Ainda que haja um cruzamento entre a precariedade e a condição precária, Butler (2018) destaca a existência de uma diferença fundamental entre ambos: o fato do segundo ser socialmente fabricado. Em suas palavras,

a condição precária designa a condição politicamente induzida na qual certas populações sofrem com redes sociais e econômicas de apoio deficientes e ficam expostas de forma diferenciada às violações, à violência e à morte. Essas populações 
estão mais expostas a doenças, pobreza, fome, deslocamentos e violência sem nenhuma proteção (p. 46).

Sendo a condição precária uma situação socialmente fabricada, podemos pensar a precarização como o produto de um cruel processo que, frente aos discursos hegemônicos da sociedade contemporânea, retira a condição de sujeito daqueles que não possuem redes de sociabilidade suficientemente alicerçadas para a manutenção do vínculo social e para a elaboração de estratégias de defesa que superem as adversidades do cenário apresentado. Ainda em decorrência da precarização, ocorre fragilização das estruturas discursivas, fruto da condição de invisibilidade e do silenciamento mortífero a que foi submetida parte da população (Rosa, 2013).

O cenário apresentado tem gerado desafios e problematizações teóricoconceituais, levando-nos a refletir sobre quais seriam os possíveis caminhos para a atuação do psicanalista junto à população em condições precárias. Se para Butler (2018) as saídas estão em torno de coligações, entendemos que a aposta da psicanálise no âmbito coletivo seja uma potente alternativa, pautada no fortalecimento de um discurso que sustente novas oportunidades de laços sociais, devolvendo-Ihes o status de sujeito.

Rosa (2013) destaca que diferentemente do trabalho analítico usual, no qual a escuta do sujeito em sofrimento o leva ao confronto de seus equívocos, devendo esse solucionar o enigma que o constitui, a atuação no contexto descrito precisa de outras estratégias de enfrentamento, seja pelos efeitos do silenciamento provocado pela condição experenciada ou pelos impasses no confronto com o discurso hegemônico. A autora ainda defende a abordagem psicanalítica clínicopolítica dentro de instituições justamente pelo seu potencial de colocar em cheque a alienação do sujeito frente a tais discursos dominantes. Nesse sentido, a escuta ofertada pelo analista deve ser no sentido de se contrapor aos mecanismos de individualização, de criminalização ou ainda de patologização desses.

Não se pode ainda deixar que considerar que o analista, para além de sua função estabelecida na relação transferencial, é também um sujeito que faz parte da cena social. Logo, está também submetido à trama citada e às relações de poder regentes da sociedade. Essa compreensão pauta a defesa de Wikinski (2019) pela

tomada de consciência de nossas próprias determinações e fantasias, nossas marcas históricas e feridas narcísicas, nossos sentimentos de ternura e compaixão, nossos próprios sentimentos de rivalidade, exclusão vergonha e ódio (p.47).

É importante ressaltar que, apesar das diferenças apontadas, Rosa (2002) não se refere à criação de novas teorias, mas sim "à construção de uma escuta clínica que leve em conta a especificidade de tais pessoas e situações" (p.149). No defendido por ela, os psicanalistas devem estar capacitados para o reconhecimento das sutis malhas de dominação que acabam por enredar os sujeitos. Somente com essa 
percepção se torna possível a diferenciação da consequência desse emaranhamento nas subjetividades do que é próprio do sujeito, objetivando a oposição a essa trama e a consequente apropriação de seu lugar social.

\section{O QUE PODE UM ANALISTA FRENTE AO PROCESSO DE PRECARIZAÇÃO E AO SEU POTENCIAL TRAUMÁTICO?}

Já sabemos que a vivência da precarização se trata de uma produção social, mas é ainda preciso apreendê-la como um fenômeno social atuante no âmbito coletivo e com efeitos no âmbito individual. Para Dejours (2000), o ataque aos alicerces da identidade precisa ser reconhecido como uma fonte de sofrimento. Nesse sentido, a vivência da precarização passa a ser vista como uma ameaça, conformando a exclusão social e gerando medo e angústia à população de forma geral. Porém, a noção de que os grupos socialmente excluídos são vítimas de uma injustiça não é senso comum. Na visão do autor, o fato do sofrimento ser compreendido como uma adversidade e não ser articulado a uma arbitrariedade, pode acarretar em sentimento de compaixão ou mesmo provocar a caridade, mas não produz indignação tampouco mobiliza protestos coletivos.

Em sua reflexão sobre os impactos subjetivos das tais situações, Dejours (2000) questiona de que forma é possível ao sujeito tolerar o intolerável. Isto é, como se torna admissível suportar o sofrimento oriundo das situações de injustiças sociais e, enquanto resposta, encontra a negação da dor como estratégia defesa psíquica. Nessa concepção, a dissociação entre a injustiça a ele infligida e o seu afeto resultante leva o sujeito a tomar uma postura de resignação, já que esse seria então "um fenômeno sistêmico, econômico, sobre o qual não se poderia exercer nenhuma influência" (p.20). Porém, é valido destacar que esse autor enfatiza que a naturalização resultante da disputa entre sofrimento e luta contra o mesmo sentimento não deve ser vista como ausência desse. Pelo contrário, o autor propõe a ideia de "normalidade sofrente" (p. 36) para nomear a tentativa de manutenção do equilíbrio psíquico, tornando o sujeito insensível ao que gera sofrimento a ele.

As referidas injustiças sociais se tratam de uma modalidade de violência na qual a ameaça não se dá sobre a integridade física dos sujeitos, mas na sua participação social. Cabe aqui, portanto, fazer uso da noção de violência simbólica cunhada por Bourdieu (1989), que se constitui como uma forma de manutenção das estruturas sociais, por meio da contínua reprodução de crenças dominantes no processo de socialização. Já que as desigualdades sociais relacionadas à condição precária, em oposição à precariedade fundamental, não são naturais, mas produzidas e reproduzidas a fim de conservar os sistemas de poder. Para o autor, os mecanismos econômicos e sociais que configuram processos de exclusão possuem graves consequências, pois, além dos sofrimentos estarem ancorados em uma realidade que dificilmente pode ser descontinuada ou transformada, o mal-estar decorrente da cruel condição social não é necessariamente evidente. Ainda que naturalizada, em uma tentativa de reduzir os seus efeitos, a violência simbólica que está por trás do processo de precarização deve ser vista como algo potencialmente traumático. 
Para compreendermos melhor a proposta apresentada, é preciso recorrermos ao pai da psicanálise. Em seu texto "Projeto para uma psicologia científica", Freud (1950[1895]/1996) utiliza o termo Nebenmensch, que pode ser traduzido por o próximo ou o homem que se situa ao lado, para fazer referência àquele que faz a intermediação entre o recém-nascido e o mundo, auxiliando-o na regulação dos seus processos psíquicos. Enquanto Hilflosigkeit, cuja tradução para português é desamparo, é o termo designado para se referir à característica dos humanos de dependência e insuficiência ao nascer. A todos é sabido que a sobrevivência do bebê humano está atrelada à presença de um cuidador, mas para Freud (1950[1895]/1996) seu papel não se esgota no cuidado, ampliando-o ao associar o processo de constituição da subjetividade a esse outro ao lado, o Nebenmensch.

Sobre o funcionamento do aparelho psíquico, Freud (1950[1895]/1996) nos ensina que esse é regido pelos princípios de inércia e de constância, os quais possuem como função reduzir ao máximo a carga de excitação recebida, percebida como desprazer, buscando o reestabelecimento da homeostase. Ao nascer, o bebê se encontra desamparado, sem recursos possíveis para efetuar qualquer ação que alivie a excitação oriunda do sistema endógeno. Para promover a descarga, é necessária uma ação específica, a qual o desamparado é incapaz de executar sem ajuda alheia. A totalidade do evento, o qual tem seu início no acúmulo dos estímulos endógenos, causado por exemplo pela fome, expresso através de um arco reflexo, como o choro, e que se encerra com a execução de movimento eficaz na remoção da tensão interna, tal como dar o leite, consiste na "experiência de satisfação" (p. 379), resultando na inscrição de um traço mnêmico no aparelho psíquico do mesmo. É essa marca, impressa somente com a presença da alteridade, que caracteriza o processo de constituição da subjetividade humana, sendo o desamparo inicial condição fundamental para a sua estruturação.

Porém, o desamparo não se encerra após o ambiente acolher as necessidades do lactante em suas primeiras experiências. Ao mesmo tempo que a condição de desamparo possui a função estruturante da subjetividade, diversas situações de desamparo podem ser vividas ao longo dos anos como desestruturantes. Acontecimentos em que a percepção de um perigo interno provoca o aumento da tensão de tal forma que o sujeito se vê incapaz de dominar a excitação geram o sentimento do desamparo (Laplanche \& Pontalis, 2001).

Outro conceito necessário para a nossa argumentação é o trauma, que para Freud (1920/1996), faz referência a uma situação que o sujeito experimenta como ameaçadora à sua vida, sendo traumático um acontecimento com tamanho impacto capaz de provocar um rompimento na vida do sujeito, não possibilitando a ele qualquer reação e extrapolando a sua possibilidade de elaboração psíquica. Ou, nas palavras de Laplanche e Pontalis (2001, p. 522), "o traumatismo caracterizase por um afluxo de excitações que é excessivo em relação à tolerância do sujeito e à sua capacidade de dominar e de elaborar psiquicamente essas excitações". 
A relação entre desamparo e o trauma é apresentada por Freud (1926/1996) em sua teoria sobre a angústia, compreendendo o estado de desamparo como protótipo da situação traumática. Um evento externo de elevada excitação, capaz de romper com o escudo protetor da psique, é percebida como situação de perigo real, fazendo com que o sujeito reviva a sua condição de desamparo ao nascer. Em tais circunstâncias, marcadas pelo excesso e pelo transbordamento da possibilidade de processamento do sujeito, é fundamental que o ambiente atue, fornecendo o sustento e os recursos necessários para a elaboração dos acontecimentos. Quando o entorno falha, não provendo o amparo necessário, estamos diante de uma situação traumática.

Rosa (2002) discorre sobre a relação do desamparo social, do desamparo discursivo e de seus efeitos traumáticos. A ausência das redes de proteção do ambiente, aqui compreendida como a insuficiência de garantias por parte do Estado acarretam na dissolução dos laços relacionais, enquanto que a tensão excessiva oriunda do medo da desproteção é vivida como desamparo social. Ainda como efeito desse perverso processo, há o desamparo discursivo, quando as estruturas discursivas não são sólidas o suficiente para manter o vínculo social. Desamparados, os sujeitos ficam vulneráveis, sem a possibilidade de, utilizando-se de recursos próprios, encontrar saídas para as situações em que se encontram (Rocha, 1999). Em suma, faltam a esses sujeitos recursos subjetivos que permitam a eles a elaboração de estratégias de defesa para a superação das dificuldades que se apresentam.

A partir da prática analítica com diferentes populações que vivem em condições precárias, tais como migrantes forçados, refugiados, adolescentes em conflito com a lei e pessoas em situação de rua, Rosa (2015) debate sobre a dimensão sociopolítica do sofrimento, a qual resulta na produção de angústia e do impedimento dos processos subjetivos. Os efeitos das diversas modalidades de violência a que estão expostos os referidos grupos acarretam na perda do laço identificatório dos semelhantes para com eles, desamparando-os socialmente. Isto é, não dispondo do amparo suficiente, acabam sem ter lugar na sociedade e são lançados para fora da política. A naturalização das suas vivências e dos seus sofrimentos acaba por enfraquecer a potência discursiva desses sujeitos que, somado ao desamparo social, vivenciam o desamparo discursivo, resultando em angústia e silêncio. Essa fragilização das estruturas discursivas acaba por não sustentar a manutenção dos vínculos sociais e, sem tem ninguém próximo a quem recorrer, conforma experiências traumáticas.

Inquietações sobre o que pode o analista frente ao contexto descrito emergiram a partir do trabalho realizado durante o desenvolvimento do projeto de iniciação científica "Jovens em situação de vulnerabilidade social: entre o trauma e o reconhecimento", financiado pela Fundação Carlos Chagas Filho de Amparo à Pesquisa do Estado do Rio de Janeiro (FAPERJ). Encontros grupais com jovens foram sistematicamente realizados, o que será melhor apresentado na sequência. Por diversas vezes, na experiência mencionada se presenciou o surgimento de 
sofrimentos que extrapolam o âmbito individual, revelando a forma como a precarização e a vulnerabilidade dos laços afetam a visão que os participantes têm de si. Temas como preconceito e rótulos irrompem o espaço de escuta, incitando diferentes afetos. Questões que envolvem o olhar do outro, julgamento e o sentimento de injustiça foram os norteadores da narrativa construída coletivamente.

Em contextos de vulnerabilidade social, Rosa (2013) entende que a direção de tratamento possível é aquela que desnaturalize as vivências de exclusão e silenciamento infligidas ao sujeito, fazendo com que ele dê sentido à sua experiência de dor, ou seja, aquilo que se configurou como traumático. Assim, o fazer psicanalítico nesses cenários se torna também uma prática clínico-política. Dessa forma, o trabalho, nesses cenários, pode visar a ressignificação da precarização e a transformação do trauma de experiência singular à experiência compartilhada. Ao analista, cabe o papel de testemunha e de transmissor da cultura.

Diante do que foi exposto, defendemos que é papel do analista atuar de forma que as experiências traumáticas, oriundas das condições precárias, sejam legitimadas e que, durante o compartilhamento dessas, a sustentação da escuta analítica opere como instrumento de cuidado e de inclusão social. A aposta dessa prática é que, em oposição à normalidade sofrente (Dejours, 2000), o grupo funcione como um ambiente seguro e acolhedor, que legitime e produza sentido para as vivências dos jovens. A expectativa é que, a partir da escuta ofertada, os participantes possam se deslocar de uma posição fixada pela condição traumática, contrapondo-se à naturalização e à invisibilidade características das situações apresentadas, e que a construção de narrativas em primeira pessoa viabilize a afetação de sentimentos até então inacessíveis a eles.

\section{O TESTEMUNHO COMO FERRAMENTA CLÍNICA}

Retomando as observações de Rosa (2013) sobre as distinções do trabalho analítico clássico e da inserção da psicanálise nos contextos apresentados, temos como premissa que a atuação do psicanalista deve ser no sentido de desenvolver estratégias de enfrentamento à naturalização das situações traumáticas vivenciadas e de seu, consequente, enfraquecimento dos laços sociais. Neste ponto, visamos pensar de que forma o fortalecimento da coletividade pode agir no sentido de possibilitar modificações nas estruturas sociais.

Broide e Broide (2016), no que se refere à função da atividade grupal em situações sociais críticas, defendem que a finalidade desse trabalho é a oportunidade de deslocamentos de circuitos fixados pelo traumático. Para os autores, essas são situações de urgências sociais que intimam a responsabilidade dos analistas perante o desamparo psíquico e social de determinadas coletividades. Dessa maneira, a criação de dispositivos grupais tem a escuta analítica como ancoragem e condição para o processo de singularização do sujeito, sendo o relato em 
primeira pessoa a potência para a transformação de um campo. Nessa visão, o grupo fornece o amparo necessário ao sujeito para tornar possível a desnaturalização das suas vivencias e o reconhecimento dos seus afetos como sofrimento.

Ao relato em primeira pessoa de uma experiência dolorosa, pode ser dado o nome de testemunho. Embora não haja um conceito unânime entre os teóricos, as discussões acerca do tema têm crescido nos últimos anos no Brasil, especialmente no que tange o debate da sua relação com a exclusão social (Ginzburg, 2008). testemunho é indicado como uma prática de linguagem que possibilita a transformação de uma narrativa em teorização viva de um campo. Ou seja, um relato que potencializa a ressignificação e a transmutação de uma posição estabelecida pelo traumático (Seligmann-Silva, 2008).

É valido pontuar que o testemunho não é um termo psicanalítico, mas que tem suas origens na literatura, inaugurada nos estudos dedicados ao Primo Levi (Ginzburg, 2008). Em seus relatos, Primo Levi une a perplexidade do que foi vivenciado à necessidade de sua expressão, o que é enfatizado por SeligmannSilva (2006) ao defender o testemunho como condição elementar para a sobrevivência daqueles que vivenciam alguma situação radical de violência. Para o autor, é a narrativa que permite o estabelecimento de um elo com os outros ou o início do seu trabalho de religamento ao mundo.

Ainda que a narrativa seja de um evento transcorrido, há no testemunho uma atualidade, conforme expressado por Vezzetti (2002), quando o autor aponta para

seu valor como intervenção no presente mais do que como fixação dos acontecimentos passados: antes de tudo, a expressão de uma vontade de sentido e de saber que nasce como resposta e oposição à enormidade de um agravo, que não se limita ao sofrimento pessoal da vítima sobrevivente (p. 188).

Considerando a visão expandida acerca do testemunho, isto é, o fato de não se esgotar na dor do sujeito, mas estar atento ao contexto que originou a experiência marcante, a atividade nomeada Tá na roda foi construída para funcionar como um espaço de escuta para a atuação em contextos de precarização. Trata-se do desenvolvimento de um dispositivo grupal de escuta para jovens em situação de vulnerabilidade social, estruturado com o intuito de promover a circulação da palavra, favorecendo a associação livre de maneira coletiva e estimulando reflexões sobre questões apresentadas pelos participantes (Klautau, 2017). A partir da relação estabelecida com o outro, espera-se fornecer subsídios ao sujeito para que ele possa dispor de meios para reconhecer, identificar, nomear e dar sentido às suas vivências, muitas vezes até então silenciadas.

Wikinski (2010) busca no latim a origem da palavra testemunha e encontra duas 
concepções. A primeira, testis, faz referência a uma terceira pessoa colocada em uma situação de litigio, na qual ela não possui qualquer envolvimento. Enquanto superstes se refere àquele que vivenciou a realidade sobre a qual ele tem que dar testemunho. Em português, assim como no espanhol, não há duas expressões distintas, tal qual no latim. A autora destaca a relação da testemunha com os formalismos do aparato jurídico e com as suas crenças na eficácia e vigor do pensamento racional, apontando para a tênue linha que se apresenta quando testis e superstes são a mesma pessoa. Assim, nos casos em que se testemunha a partir de relatos em primeira pessoa, ocorre o rompimento de qualquer suposta posição objetiva e neutra esperada de uma testemunha (WIKINSKI, 2019).

Para a nossa discussão, a diferenciação entre o testemunho e o testemunhar é bastante significativa. $\mathrm{O}$ primeiro termo, como apresentado, faz referência ao ato testemunhal ou, em outras palavras, ao depoimento em primeira pessoa de alguma vivência pessoal. Enquanto que o testemunhar diz respeito a quem escuta o testemunho narrado. Gagnebin (2006) destaca que a função de testemunhar está para além de presenciar o fato em si, pois se refere àquele que se faz presente durante a narrativa do insuportável, sustentando a escuta e disposto a transmitir tais palavras a outros,

não por culpabilidade, ou por compaixão, mas porque somente a transmissão simbólica, assumida apesar e por causa do sofrimento indizível, somente essa retomada reflexiva do passado pode nos ajudar a não repeti-lo infinitamente, mas a ousar esboçar uma outra história, a inventar o presente (p. 57).

No decorrer dos encontros do Tá na roda, a grande mobilização que acontecia entre os participantes no momento em que os testemunhos emergiam, passou a chamar a nossa atenção. Frente ao ato testemunhal, ou seja, na posição de testemunha, os demais jovens se apropriavam do espaço, organizando-se espontaneamente. Enquanto um compartilhava alguma situação vivenciada, outros se implicavam a ponto de, inspirados no discurso do outro, também darem seus testemunhos. Era possível observar que o acolhimento da narrativa dolorosa os aproximava, potencializando o vínculo entre eles e, ainda, abria espaço para também reconhecer o seu sofrimento e compartilhar as suas experiências singulares.

O movimento observado no grupo é semelhante ao indicado por Kupermann (2009), quando considera o testemunho como um dispositivo de identificação empática, justamente pela sua capacidade de ligação, que ocorre pela via da identificação, associado a um elemento de ordem reflexiva. Há, por um lado, uma grande dificuldade de se falar da experiência traumática. Porém, por outro lado, o fato de a tornar pública abre espaço que pode contaminar de forma positiva. Pois, ao colocar na roda, torna-se possível ao sujeito elaborar a memória da vivência negativa e ainda desenvolver uma consciência coletiva. 
A fim dar sustentação às ideias expostas, será apresentado a dinâmica ocorrida durante um dos encontros, quando uma menina, em meio a lágrimas e bastante mobilizada, dá o seguinte testemunho:

Meu pai morreu quando eu era muito pequena, eu nem lembro dele. Mas o amor que sinto por ele foi construído, a partir de fotos, de histórias que me contam sobre ele, das lembranças que ele deixou e passam para mim. E eu sinto muito a falta dele.

Durante a sua narrativa, o grupo todo silenciou e a escutou. Esse grupo, em especial, era grande e dificilmente se conseguia fazer com que mantivessem o silêncio enquanto outro colega falasse, ou mesmo alguma das analistas. A exposição de algo, não somente íntimo, como também bastante doloroso, teve grande efeito nos demais. Nesse momento, uma questão foi colocada na roda: "Qual a sua falta?". Esta serviu de disparador e propiciou o surgimento de outros testemunhos - todos em torno de perdas dos pais e nas formas de lidar com a falta dessas figuras tão importantes.

A partir da questão destacada, uma participante começou a narrar sua experiência de perda. Conta que seu pai havia morrido quando ela era um pouco maior que a colega. Portanto, tinha algumas poucas lembranças dele, mas ressalta que a sua adolescência foi um período conturbado.

"Passei a responder à minha mãe. Fiquei muito revoltada! Mas minha mãe não me dava mole. Era rígida comigo e depois essa fase passou".

Após dar o testemunho referente a falta de seu pai, a participante afirmou ser religiosa. Por conta disto, acredita que Deus supre essa falta do pai na Terra e que a mãe também faz esse papel. Na sequência, outro participante toma a palavra e diz que perdeu seu pai na adolescência. Tem muitas lembranças boas dele, assim como seus primos e amigos. Define o pai como uma pessoa muito brincalhona e querida por todos.

"Hoje sou pai e tento ser para o meu filho o que meu pai foi para mim. Ele é a minha referência do que desejo ser".

Já próximo do tempo acabar, emergiu mais um testemunho. Dessa vez de uma jovem que não conheceu os seus pais biológicos. Um está morto e o outro preso. Foi criada pelos seus tios, que são para ela seus pais de verdade.

"Eles me dão amor, carinho e cuidado. Nem sinto falta dos meus pais de verdade".

Se, entre os pares, o testemunhar cumpre a função identificatória, impulsionando a desnaturalização de sentimentos e o fortalecendo dos laços entre eles, cabe ao 
analista a legitimação dos afetos que passam a ser expressos através das palavras. Assim, o interesse do analista diante do ato testemunhal reside no conteúdo latente que emerge durante a narrativa que expõe acontecimentos históricos, econômicos e políticos. Em outras palavras, o analista deve estar atento à singularidade que se manifesta enquanto o sujeito torna pública a sua experiência. Dessa forma, cabe ao analista não ouvir simplesmente uma sequência de acontecimentos, mas ser capaz de escutar o que há por detrás do seu discurso e qual o efeito do seu relato (Wikinski, 2019; Broide \& Broide, 2016).

Nesse artigo, o que se pretende defender é o uso do testemunho como uma potente ferramenta clínica para o trabalho do analista em contextos cuja a condição precária se configura como marca patente. A partir da experiência obtida durante o trabalho de campo, percebeu-se a potência do ato testemunhal e a possibilidade desse funcionar como uma espécie de força impulsora do trabalho no âmbito coletivo, promovendo um intercâmbio de identificações catalisadas pelo narrar em primeira pessoa e, por fim, o reconhecimento de sentimentos até então silenciados. Nessa linha, pode-se dizer que o testemunho atua no resgate do direito da primeira pessoa do discurso, permitindo a ela uma guinada subjetiva, como se refere Wikinski (2019), possível àquele que adquire conhecimento e passa a ser reconhecido pela História.

Considerando, então, que através do ato testemunhal emergem sentimentos naturalizados que, ao serem retirados da invisibilidade, são capazes de despertar afetos e incitar à reflexão, podemos o compreender como uma tentativa de elaboração psíquica de uma marca traumática. Em outras palavras, o testemunho emerge como propulsor do trabalho, no que se refere ao esforço realizado pelos mecanismos psíquicos, por meio de transformações das representações do vivido (Seligmann-Silva, 2019). Assim, por meio do testemunho, o sujeito pode desnaturalizar e ressignificar as suas experiências. Do reconhecimento das adversidades do ambiente, se torna possível a oposição ao processo de precarização e a, consequente, apropriação do seu lugar social.

A visão apresentada dialoga com o defendido por Rosa (2002, 2012), quando afirma que o analista, perante o testemunho e o resgate da memória, é convocado a suportar a narrativa e fazer a função de propulsor de ressignificações. Isto é, por meio da escuta ofertada na presença do analista se torna possível a ultrapassagem de obstáculos que culminam com o resgate da experiência e o compartilhamento dessa com o outro. Dessa forma, o analista possibilita a ressignificação do traumático e a sua escuta se configura como instrumento de cuidado e de transformação social.

Por fim, podemos afirmar que a experiência se apresentou como um terreno bastante fértil para o trabalho do analista. Considerando a premissa apresentada por Rosa (2002), de que a precarização acaba por fragilizar as estruturas discursivas, sendo essas insuficientes para a manutenção do laço social, reiteramos a potência da atuação no âmbito coletivo como possibilidade de contraposição dessa 
perversa e excludente lógica. Pois, a construção de espaço de escuta propicia a formação de vínculos, favorecendo os processos de identificações e de diferenciações, e ainda oferece o suporte para o desenvolvimento de recursos subjetivos aos participantes, por meio da composição de uma rede de significantes que possibilitem a atribuição de novos sentidos.

\section{CONSIDERAÇÕES FINAIS}

Acreditamos que a psicanálise tem muito a contribuir para a prática nas políticas públicas e também na busca de novas formas de atendimento, especialmente no âmbito do coletivo. Se entendemos que a condição precária vivida por determinados grupos não é natural, mas sim fabricada e ainda que essa experiência gera graves desdobramentos nas estruturas sociais, fazer oposição à sua manutenção também se torna viável. Isto é, se existiu mecanismos para a sua criação e há meios para a sua perduração, a sua desconstrução também é possível.

A natural emergência dos testemunhos demonstra que, por mais que se tente naturalizar, ou banalizar o sofrimento, o desejo e a busca por reconhecimento operam quando construído um espaço seguro e acolhido, tornando a escuta do psicanalista um potente instrumento de cuidado e de garantia do laço social. Portanto, dar espaço para que o sujeito possa falar em nome próprio, sustentar a escuta durante a narrativa da dor, legimitar o seu sofrimento e estar disposto a transmitir o outro lado da história, são atribuições do analista na função de testemunhar. É nesse exercício que está ancorada a estratégia para a ressignificação do que foi vivido como traumático e para a reinvenção de finais.

\section{REFERÊNCIAS}

Bourdieu, P. (1989). O poder simbólico. Rio de Janeiro, RJ: Bertrand.

Broide, J., \& Broide, E. E. (2016). A psicanálise em situações sociais críticas: metodologia clínica e intervenções ( $2^{\mathrm{a}}$ ed.). São Paulo, SP: Escuta.

Butler, J. (2018). Quadros de guerra: quando a vida é passível de luto? (5a ed.). Rio de Janeiro, RJ: Civilização Brasileira.

Dejours, C. (2000). A banalização da injustiça social (3a ed.). Rio de Janeiro, RJ: FGV Editora

Dunker, C. I. L. (2016, 17 de fevereiro). Políticas de identidade e a busca de um novo modelo de crítica. Revista Fórum. Recuperado de https://revistaforum.com.br/noticias/christian-dunkerpoliticas-de-identidade-e-a-busca-de-um-novo-modelo-de-critica/

Ferreira, A. B. H. (1986). Novo dicionário Aurélio da língua portuguesa. Rio de Janeiro, RJ: Nova Fronteira.

Freud, S. (1996). Projeto para uma psicologia científica. In Edição Standard Brasileira das Obras Psicológicas Completas de Sigmund Freud. Vol. I. Rio de Janeiro, RJ: Editora Imago. (Trabalho original publicado em 1950[1885]).

Freud, S. (1996). Além do princípio de prazer. In Edição Standard Brasileira das Obras Psicológicas Completas de Sigmund Freud. Vol. XVIII. Rio de Janeiro, RJ: Imago Editora. (Trabalho original publicado em 1920).

Freud, S. (1996). Inibições, sintomas e ansiedade. In Edição Standard Brasileira das Obras Psicológicas Completas de Sigmund Freud. Vol. XX. Rio de Janeiro, RJ: Imago Editora. (Trabalho original publicado em 1926).

Gagnebin, J. M. (2006). Lembrar escrever esquecer. São Paulo, SP: Editora 34.

Ginzburg, J. (2008). Linguagem e trauma na escrita do testemunho. Revista Conexão Letras, 3(3), 1-6. doi: $10.22456 / 2594-8962.55604$ 
Klautau, P. (2017). O método psicanalítico e suas extensões: escutando jovens em situação de vulnerabilidade social. Revista Latinoamericana de Psicopatologia Fundamental, 20(1), 113127. doi: 10.1590/1415-4714.2017v20n1p113.8

Kupermann, D. (2009). Figuras do cuidado na contemporaneidade: testemunho, hospitalidade e empatia. In Maia, M. S. (Org.). Por uma ética do cuidado (pp. 185-204). Rio de Janeiro, RJ Garamond.

Laplanche, J, \& Pontalis, J.-B. (2001). Vocabulário de psicanálise (4ª ed.). São Paulo, SP: Martins Fontes. (Trabalho original publicado em 1987)

Rocha, Z. (1999). Desamparo e metapsicologia: para situar o conceito de desamparo no contexto da metapsicologia freudiana. Síntese Revista de Filosofia, 26(86), 331-346. Recuperado de http://www.faje.edu.br/periodicos/index.php/Sintese/article/view/761

Rosa, M. D. (2002). Uma escuta psicanalítica das vidas secas. Revista Textura, 2(2), 42-47. Recuperado de https://www.academia.edu/download/43218022/Uma-escuta-psicanalitica-das-vidassecas-Miriam-Debieux.pdf

Rosa, M. D. (2012). Migrantes, imigrantes e refugiados: a clínica do traumático. Revista de Cultura e Extensão USP, 7, 67-76. doi: 10.11606/issn.2316-9060.v7i0p67-76

Rosa, M. D. (2013). Psicanálise implicada vicissitudes das práticas clinicopolíticas. Revista do Associação Psicanalítica de Porto Alegre, 41, 29-40. Recuperado de http://www.appoa.com.br/uploads/arquivos/revistas/revista41.pdf

Rosa, M. D. (2015). Psicanálise, política e cultura: a clínica em face da dimensão sócio-política do sofrimento (Tese de livre-docência). Instituto de Psicologia, Universidade de São Paulo, São Paulo.

Seligmann-Silva, M. (2006). Novos escritos dos cárceres: uma análise de caso. Luiz Alberto Mendes, Memórias de um sobrevivente. Estudos de literatura brasileira contemporânea, (27), 35-58. Recuperado de https://dialnet.unirioja.es/servlet/articulo? codigo $=4846220$

Seligmann-Silva, M. (2008). Narrar o trauma: a questão dos testemunhos de catástrofes históricas. Psicologia clínica, 20(1), 65-82. doi: 10.1590/S0103-56652008000100005

Seligmann-Silva, M. (2019). O que resta do testemunho. In Wikinski, M. O trabalho da testemunha: Testemunho e experiência traumática. São Paulo, SP: Annablume Editora.

Vezzetti, H. (2002). Pasado y presente: guerra, dictadura y sociedad en la Argentina. Buenos Aires, Argentina: Siglo XXI.

Wikinski, M. (2010). El testigo/superstes ante la justicia. Presentado en III Seminario Internacional Políticas de la Memoria. Centro Cultural Haroldo Conti, Buenos Aires, Argentina.

Wikinski, M. (2019). O trabalho da testemunha: Testemunho e experiência traumática. São Paulo, SP: Annablume Editora.

\section{CONFLITOS DE INTERESSES}

Não há conflito de interesses.

\section{FINANCIAMENTO}

Fundação Carlos Chagas Filho de Amparo à Pesquisa do Estado do Rio de Janeiro (FAPERJ).

\section{SOBRE OS AUTORES}

Maria Manuela Dias Ramos de Macedo é psicóloga pela Universidade Veiga de Almeida, mestranda em Educação pela Universidade Federal Fluminense e Membro Associado em Formação do Círculo Psicanalítico do Rio de Janeiro.

E-mail: mariamanuelarm@gmail.com

(iD) https://orcid.org/0000-0003-0476-5951 
Perla Klautau é Professora do Instituto de Psicologia da Universidade Federal do Rio de Janeiro, Psicanalista, Membro Efetivo do Círculo Psicanalítico do Rio de Janeiro

E-mail: pklautau@uol.com.br

(iD) https://orcid.org/0000-0003-4578-0795 